\title{
Letter to the Editor concerning the Article "Adolescent Idiopathic Scoliosis: A 71 Cases Study Ascertaining That Straightening Is Possible, and a New Etiological Hypothesis"
}

\author{
Fabio Zaina ${ }^{1}$, Michele Romano ${ }^{1}$, Sabrina Donzelli ${ }^{1}$, Stefano Negrini ${ }^{2,3}$ \\ ${ }^{1}$ ISICO (Italian Scientific Spine Institute), Milan, Italy \\ ${ }^{2}$ Department of Clinical and Experimental Sciences, University of Brescia, Brescia, Italy \\ ${ }^{3}$ IRCSS Don Gnocchi Foundation, Milan, Italy
}

Dear Editor,

We read with interest the paper by Polak [1], showing incredible improvement of scoliosis with a manual therapy technique. Nevertheless, there are some methodological biases that greatly concern us: many details are missing, and the conclusions are far from supported by the data.

First, the selection bias. Scoliosis is a three-dimensional deformity of the vertebrae and trunk, not just a postural matter, diagnosed through the presence of the hump, then confirmed by radiographs [2,3]. Most of the patients in the study had curves between $11^{\circ}$ and $19^{\circ} \mathrm{Cobb}$, where the presence of non-structural scoliosis is higher: no data were reported about the Adams test [2], while the author stated he excluded postural problems without saying how. Since the author supposes that neck contracture caused scoliosis (this is not supported by current knowledge about structural scoliosis etiology [4]), we can imagine that many of these were simply antalgic scoliosis. Moreover, information about the patients' selection, drop out, and failures is missing, so it's possible that non respond- ers were excluded. These selection biases make the conclusions unreliable.

Other biases typical of scoliosis treatment:

The follow-up period is too short, and shows no end of growth results. This has been clearly stated recently as an important factor in scoliosis conservative treatment [5]. Some patients had their outcomes after 2 weeks, making it impossible to determine the stability of the result. Even accepting muscular imbalance as the cause, and this has never been proved, short-term realignment of the spine is not enough to remove the deformation since bones take a long time to recover.

Improper use of the term adolescent idiopathic scoliosis. The author included juveniles, adolescents, and probably end of growth patients. Since they have very different short-term risks of progression $[2,3,6]$, they must be studied separately. Juvenile scoliosis is not very aggressive in short time before the pubertal growth spurt; in the oldest group (>16 years), we expect the growth to be already concluded, so a short-term improvement doesn't really change the deformity. Large changes in Cobb angle can

Received Dec 22, 2014; Accepted Dec 22, 2014

Corresponding author: Fabio Zaina

ISICO (Italian Scientific Spine Institute), via Roberto Bellarmino 13/1-20141 Milan, Italy

Tel: +39-0381-310851, Fax: +39-0291-390842, E-mail: fabio.zaina@isico.it 
occur even during the same day: large curves in adults tend to be 6-7 degrees lower in the morning with respect to the evening [7], and specific exercises can improve posture up to $20^{\circ}$ [8].

The Risser test, the gold standard for spinal growth evaluation, was ignored [3,5].

The only conclusion supported by the present data could be that the technique provided very short-term postural benefits. No conclusions about end of growth results and or structural scoliosis can be drawn. The etiological theory was not demonstrated: beyond the biases reported, successfully applying a treatment doesn't make its founding theory correct. The effect of the treatment is probably a provisional postural change, and not an improvement of any deformity. Proposing this technique alone as an alternative to bracing is not supported by data, and can be totally misleading for readers; moreover, bracing has been shown to be effective not just in stopping, but even in improving the condition $[6,9,10]$.

\section{Conflict of Interest}

No potential conflict of interest relevant to this article was reported.

\section{References}

1. Polak J. Adolescent idiopathic scoliosis: a 71 cases study ascertaining that straightening is possible, and a new etiological hypothesis. Asian Spine J 2013;7: 282-8.
2. Hresko MT. Clinical practice. Idiopathic scoliosis in adolescents. N Engl J Med 2013;368:834-41.

3. Negrini S, Aulisa AG, Aulisa L, et al. 2011 SOSORT guidelines: Orthopaedic and Rehabilitation treatment of idiopathic scoliosis during growth. Scoliosis 2012; 7:3.

4. Dayer R, Haumont T, Belaieff W, Lascombes P. Idiopathic scoliosis: etiological concepts and hypotheses. J Child Orthop 2013;7:11-6.

5. Richards BS, Bernstein RM, D'Amato CR, Thompson GH. Standardization of criteria for adolescent idiopathic scoliosis brace studies: SRS Committee on Bracing and Nonoperative Management. Spine (Phila Pa 1976) 2005;30:2068-75.

6. Weinstein SL, Dolan LA, Wright JG, Dobbs MB. Effects of bracing in adolescents with idiopathic scoliosis. N Engl J Med 2013;369:1512-21.

7. Beauchamp M, Labelle H, Grimard G, Stanciu C, Poitras B, Dansereau J. Diurnal variation of Cobb angle measurement in adolescent idiopathic scoliosis. Spine (Phila Pa 1976) 1993;18:1581-3.

8. Negrini A, Parzini S, Negrini MG, et al. Adult scoliosis can be reduced through specific SEAS exercises: a case report. Scoliosis 2008;3:20.

9. Negrini S, Minozzi S, Bettany-Saltikov J, et al. Braces for idiopathic scoliosis in adolescents. Cochrane Database Syst Rev 2010;(1):CD006850.

10. Lusini M, Donzelli S, Minnella S, Zaina F, Negrini S. Brace treatment is effective in idiopathic scoliosis over 45 degrees: an observational prospective cohort controlled study. Spine J 2014;14:1951-6. 